\title{
A heat waste recovery system via thermoelectric generator
}

\author{
Chai-Phing Chen, Siaw-Paw Koh, Sieh-Kiong Tiong, Jian-Ding Tan, Albert Yu-Chooi Fong \\ Institute of Sustainable Energy, Universiti Tenaga Nasional, Malaysia
}

\begin{tabular}{l} 
Article Info \\
\hline Article history: \\
Received Oct 1, 2018 \\
Revised Feb 10, 2019 \\
Accepted May 13, 2019 \\
\hline
\end{tabular}

\section{Keywords:}

Energy efficiency

Heat waste recovery

Thermoelectric generator

\begin{abstract}
Be it in the power production or consumption end, improvement on the power efficiency has become one of the most pivoting research topics over the past few decades. In order to reduce the reliance on fossil fuels and negative impacts on the environment, many ways are found to show promising results to increase power efficiency. One of the most effective ways is to recover and reuse heat waste. In this research, a heat waste recovery system is proposed by using thermoelectric generators (TEGs). This proposed heat recovery system can be implemented at the exhaust or the chiller section of a power system to abstract the excessive and unwanted heat and reuse it before it dissipates into the environment or goes to waste. Experiments are setup and conducted with controlled heat levels to investigate the performance of the proposed system in converting heat waste into electricity under different temperatures. The results show that the generated power hikes as the heat set-points increase from $30^{\circ} \mathrm{C}$ to $240^{\circ} \mathrm{C}$. The output power fluctuates and shows no significant increase as the temperature increases from $240^{\circ} \mathrm{C}$ onwards. The maximum power is generated at $290^{\circ} \mathrm{C}$. It can thus be concluded that the proposed system successfully generates electricity under different level of heat waste temperature. In time to come, this research can further explore the possibility on the optimization of the generated power.
\end{abstract}

Copyright $\odot 2019$ Institute of Advanced Engineering and Science. All rights reserved.

\section{Corresponding Author:}

Jian-Ding Tan,

Institute of Sustainable Energy,

Universiti Tenaga Nasional, Malaysia.

Email: tjianding@uniten.edu.my

\section{INTRODUCTION}

In the field of energy and power, energy efficiency has always been a crucial and critical topic. In a practical real world, the issue of energy efficiency in power production companies is more often than not overshadowed by other imperative considerations, such as economic and financial weightage [1]. While it is understandable that not all improvement on energy efficiency can promise financial benefits, the study and research in this topic can still prove to be pivoting in the long run to cut down fossil fuel consumption and to reduce the impact on the environmental at the same time. It can be found in the literature that reducing energy consumption is one of the major keys in improving the energy efficiency. A reduction in the total activity of a production line can help achieving this [2] without dire economic or financial impact on a company [3] but may require a drastic change to the business model. This can prove to be highly unsuitable for certain company types [4]. Energy management is another way out. It has been explored at a number of studies and is found to be suitable for long, medium and short-term energy consumption improvements [5]. Recent advancements also showed the implementations of artificial intelligent and soft computing techniques in enhancing the efficiency of energy productions and handling [6-11]. Besides all these, another solution to ensure a higher energy efficiency is through heat waste recovery [12]. Heat waste recovery and reuse systems are based on the principle that energy is never actually consumed but only converted from one form to another. There is a high potential to capture this and utilize it as an energy supply. Literature studies 
show that there are several possible means to recycle precious heat energy before it goes to waste [13]. In this research, a heat waste recycling mechanism is proposed by implementing the thermoelectric generator (TEG).

A TEG is also known as a Seebeck generator. It is a solid-state device that converts temperature difference into electrical energy. The general operation is based on Seebeck effect, in which a temperature difference between two different electrical conductors or semiconductors produces a voltage difference between the two substances [14]. Unlike many other power generators, the TEG functions under a solid state as it has no moving parts [15]. This in turn grants the TEG it several advantages, such as higher reliability and robustness, which can prove to be crucial and very helpful in many applications. Literature study shows that higher temperature different between the two sides of the TEG yields relatively higher output power [16-18]. Extensive research and studies are needed to further enhance the TEG systems to ensure a relatively higher power conversion efficiency and to overcome several related issues, such as thermal contact resistance, the Peltier effect and the Thomson effect [19]. A rich literature can be found on the advancements of TEG related applications. Many of which proposed modifications and methods to ensure the efficiency of the system [20-25].

In this paper, a heat waste recovery system is proposed using TEG modules. The general idea is to implement the proposed heat recovery system at the exhaust section of a power system to abstract and recycle precious heat before it is discarded into the environment and goes to waste. The paper is sectioned into four major chapters. Chapter two explains the proposed design layout in detail. The designed system is then tested in experiments. The setup and results of the experiments are discussed in Chapter three. Chapter four offers the conclusions drawn from the tests and experiment findings.

\section{SYSTEM DESIGN LAYOUT}

Generally speaking, a TEG module generates electricity when there is a temperature difference between the two opposite sides. In the application of a heat recovery system, the basic idea is to apply the heat waste to one side of the TEG module while cooling the other side as effective as possible. In this research, an experiment is set up to test the performance of the TEG modules under different heat waste condition.

In order to mimic the conditions from a heat waste source, an electronic-controlled heater is used. A temperature sensor is attached to the side of the TEG modules close to the heat source to monitor the temperature level. A water-cooled heat sink is used to cool one side of the TEG modules to further increase the temperature difference between the two sides of the TEG modules. The generated power goes through a power meter to monitor the generated power before being fed to the load. A lamp is used as the load for the purpose of this experiment. An array of eight TEG modules is employed in this setup. Figure 1 illustrates the design of the system in details.

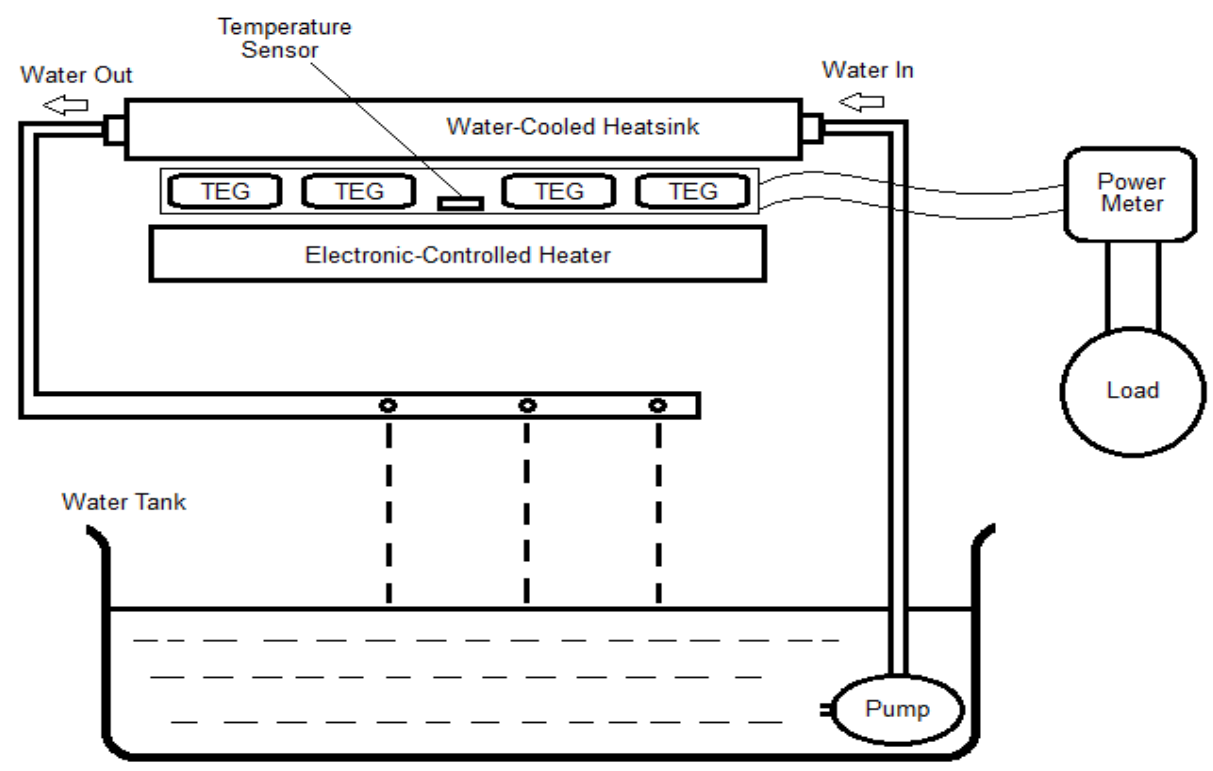

Figure 1. The layout of the system design 
Upon powering up the system, the pump will pump the water from the tank to flow through the heat sink at the rate of $2.9 \mathrm{~L} /$ minute, transferring the heat away, which in turn chill the cool side of the TEG modules. The water carrying the assistive heat from the heat sink will then be sprinkled back into the tank, dissipating the heat into the environment in the process. The heater is controlled to the temperature required in different tests and simulations in the experiment. The power meter indicates and records the output power generated under different settings.

\section{EXPERIMENTAL RESULTS AND ANALYSIS}

Experiments are conducted to test and investigate the performance of the developed system. The ambient temperature in which the system was set-up was measure to be $25^{\circ} \mathrm{C}$. The power generated by the system is recorded with each $10^{\circ} \mathrm{C}$ increment of the heater, beginning with $30^{\circ} \mathrm{C}$. Ten individual runs are conducted to avoid discrepancy. The averaged values are analyzed. Table 1 shows the average power generated by the system with different heat levels.

Table 1 . The generated power in Watt by the system under different heat conditions.

\begin{tabular}{|c|c|c|c|}
\hline Temperature $\left({ }^{\circ} \mathrm{C}\right)$ & Generated Power (W) & Temperature $\left({ }^{\circ} \mathrm{C}\right)$ & Generated Power (W) \\
\hline 30 & 0.3 & 170 & 38.8 \\
\hline 40 & 0.7 & 180 & 47.2 \\
\hline 50 & 1.2 & 190 & 51.7 \\
\hline 60 & 3.1 & 200 & 58.1 \\
\hline 70 & 5.4 & 210 & 63.2 \\
\hline 80 & 9.8 & 220 & 78.7 \\
\hline 90 & 10.2 & 230 & 89.1 \\
\hline 100 & 11.3 & 240 & 95.2 \\
\hline 110 & 15.9 & 250 & 97.8 \\
\hline 120 & 21 & 260 & 98.1 \\
\hline 130 & 25.7 & 270 & 98.9 \\
\hline 140 & 26.9 & 280 & 99.7 \\
\hline 150 & 29.2 & 290 & 101.3 \\
\hline 160 & 31.6 & 300 & 100.1 \\
\hline
\end{tabular}

It can be observed from the table that the system successfully generated electricity from the given heat source. A significant and steady increment is recorded on the output power as the temperature of the heater increases. Upon reaching $240^{\circ} \mathrm{C}$, the reading continues to climb, but the increment has significantly slowed down. The maximum output power is recorded at $290^{\circ} \mathrm{C}$. Any further increment of the heat does not give any significant hike in the output power generated.

The graph in Figure 2 illustrate a better picture of the experiment reading in the form of graph. The increment of the reading can be seen more clearly in the graph plots. Observe the rapid hike at the beginning of the graph from $30^{\circ} \mathrm{C}$ to around $240^{\circ} \mathrm{C}$. The increment is significantly lesser from $240^{\circ} \mathrm{C}$ towards the end of the graph with minor fluctuations.

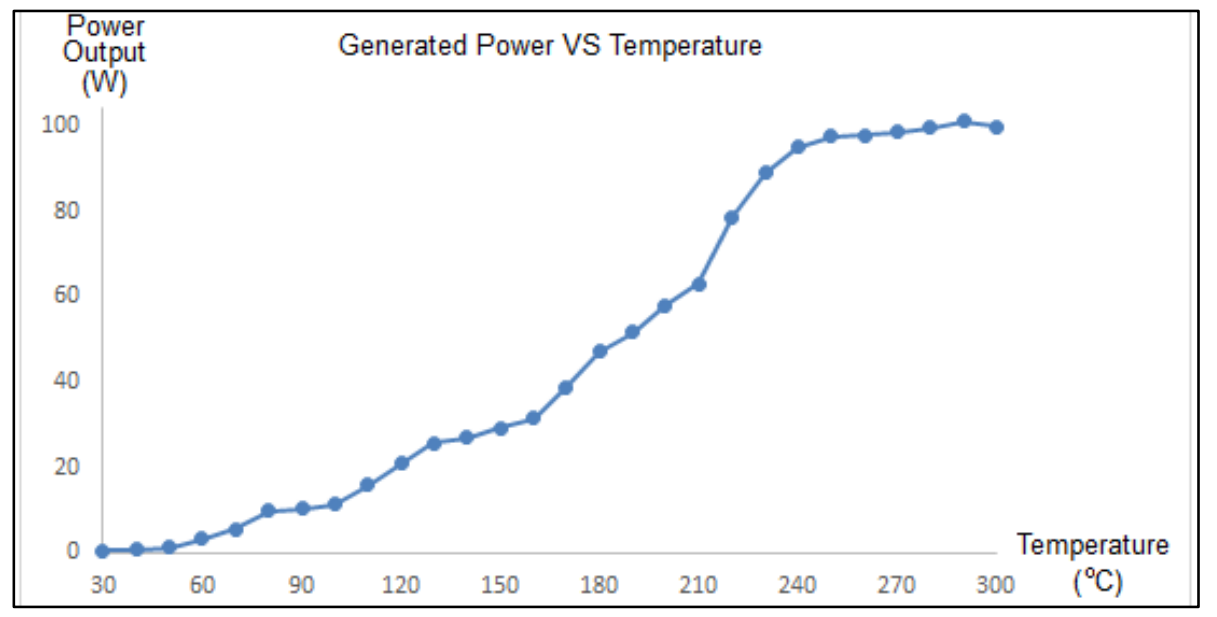

Figure 2. Power generated under different heat levels 


\section{CONCLUSION}

In this research, a waste recovery system is proposed by using thermoelectric generator arrays. Experiments are conducted to investigate the performance of the proposed system in converting heat waste into electricity under different heat levels. The results show increments in the output power as the heat climbs from $30^{\circ} \mathrm{C}$ to around $240^{\circ} \mathrm{C}$. From $240^{\circ} \mathrm{C}$ onwards the output power level fluctuates without any significant hike. The maximum output electricity is recorded at $290^{\circ} \mathrm{C}$. We can thus conclude that the proposed system performs well in converting heat waste into electricity. Several other aspects can be looked into in future research on this topic, including the maximum power point tracking of multiple TEG modules application, and the arrangement patterns optimization of the TEG modules

\section{ACKNOWLEDGEMENTS}

The authors express great acknowledgement to Universiti Tenaga Nasional (UNITEN), Malaysia for the support of this research under the UNIIG internal research grant.

\section{REFERENCES}

[1] D. Chiaroni, et al., "Introducing a new perspective for the economic evaluation of industrial energy efficiency technologies: an empirical analysis in Italy," Sustain Energy Technol Assess, vol. 15, pp. 1-10, 2016.

[2] S. Sorrell, "Reducing energy demand: a review of issues, challenges and approaches," Renew Sustain Energy Rev., vol. 47, pp. 74-82, 2015.

[3] A. Tukker, "Eight types of product service system: eight ways to sustainability?" Experiences from SusProNet. Bus Strategy Environ, vol. 13, pp. 246-260, 2004.

[4] A. Neely, "Exploring the financial consequences of the servitization of manufacturing," Oper Manage Res., vol. 1, pp. 103-118, 2008.

[5] Y. Seow and S. Rahimifard, "A framework for modelling energy consumption within manufacturing systems," CIRP J Manuf Sci Technol, vol. 4, pp. 258-264, 2011.

[6] R. Islam, et al., "An approach to building energy clusters using particle swarm optimization algorithm for allocating the tasks in computational grid," Indonesian Journal of Electrical Engineering and Computer Science, vol. 14, pp. 826-833, 2019.

[7] J. D. Tan, et al., "An Electromagnetism-like Mechanism Algorithm Approach for Photovoltaic System Optimization," Indonesian Journal of Electrical Engineering and Computer Science, vol. 12, pp. 333-340, 2018.

[8] J. D. Tan, et al., "Implementation of Voltage Optimization for Sustainable Energy," Indonesian Journal of Electrical Engineering and Computer Science, vol. 12, pp. 341-347, 2018.

[9] J. D. Tan, et al., "An artificial intelligent approach for the optimization of organic rankine cycle power generation systems," Indonesian Journal of Electrical Engineering and Computer Science, vol. 14, pp. 340-345, 2019.

[10] C. P. Chen, et al., "Online Support Vector Based Gas Emission Prediction System for Generaton Power Plant," Journal Fundam Appl Sci., vol. 10, pp. 472-485, 2018.

[11] A. Yani, et al., "Optimum reactive power to improve power factor in industry using genetic algortihm," Indonesian Journal of Electrical Engineering and Computer Science, vol. 14, pp. 751-757, 2019.

[12] H. Vallack, et al., "Technology innovation for energy intensive industry in the United Kingdom," New York, Low Carbon Futures, 2011.

[13] E. Woolleya, et al., "Industrial waste heat recovery: A systematic approach," Sustainable Energy Technologies and Assessments, vol. 29, pp. 50-59, 2018.

[14] S. Lineykin and S. B. Yaakov, "Modeling and Analysis of Thermoelectric Modules," Twentieth Annual IEEE Applied Power Electronics Conference and Exposition, APEC, vol. 3, pp. 2019-2023, 2005.

[15] N. D. Trip, et al., "Considerations on the Use of Thermoelectric Generators at low Temperatures to recover Waste Geothermal Energy," 14th International Conference on Engineering of Modern Electric Systems (EMES), pp. 248$251,2017$.

[16] C. Liu, et al., "A 1 KW Thermoelectric Generator for Lowtemperature Geothermal Resources," Proceedings, Thirty-Ninth Workshop on Geothermal Reservoir Engineering Stanford University, Stanford, California, pp. 1-12, 2014.

[17] A. Montecucco, et al., "Solution to the 1-D unsteady heat conduction equation with internal Joule heat generation for thermoelectric devices," Applied Thermal Engineering, vol. 35, pp. 177-184, 2012.

[18] F. Felgner, et al., "Component-Oriented Modeling of Thermoelectric Devices for Energy System Design," IEEE Transactions on Industrial Electronics, vol. 61, pp. 1301-1310, 2014.

[19] J. Sim, et al., "Voltage Stabilization of Thermoelectric Modules using a Boost Converter," International Journal of Mechanical \& Mechatronics Engineering IJMME-IJENS, vol. 15, pp. 115-122, 2015.

[20] R. Bjork, et al., "Analysis of the internal heat losses in a thermoelectric generator," International Journal of Thermal Sciences, vol. 85, pp. 12-20, 2014.

[21] T. Caillat, et al., "Development of high efficiency thermoelectric generators using advanced thermoelectric materials," AIP proceedings, vol. 420, pp. 1647-1651, 1998.

[22] M. B. A. Bashir, et al., "Recent advances on $\mathrm{Mg}_{2} \mathrm{Si}_{1-\mathrm{X}} \mathrm{Sn}_{\mathrm{X}}$ for Thermoelectric generation," Renewable and Sustainable Energy Reviews, vol. 37, pp. 569-584, 2014. 
[23] H. K. Ma, et al., "Waste heat recovery using a thermoelectric power generation system in a biomass gasifier," Applied Thermal Engineering, 2014.

[24] A. Montecucco and A. R. Knox, "Maximum Power Point Tracking Converter Based on the Open-Circuit Voltage Method for Thermoelectric Generators," IEEE Transactions on Power Electronics, vol. 30, pp. 828-839, 2015.

[25] A. Montecucco, et al., "The effect of temperature mismatch on thermoelectric generators electrically connected in series and parallel," Applied Energy, vol. 123, pp. 47-54, 2014. 